\title{
TRAM TRACK MAINTENANCE-PLANNING BY GAUGE DEGRADATION MODELLING
}

\author{
Maja Ahac, Stjepan Lakušić \\ Dept of Transportation Engineering, Faculty of Civil Engineering, University of Zagreb, Croatia
}

Submitted 28 April 2015; resubmitted 21 May 2015; accepted 27 September 2015

\begin{abstract}
Tram track system management is a complex, costly and interdisciplinary process. It involves construction, monitoring and maintenance of track infrastructure and rolling stock, and public transport organization. Track management cost reduction requires development of a modern management system that is based on integration and mutual complementarity of engineering and maintenance activities. The first step of its establishment is increasing the proportion of planned predictive-preventive track maintenance at the expense of corrective maintenance. This requires creation of a maintenance-planning model. Its basic prerequisite is the development of a mathematical model of tram track degradation during exploitation. The research presented in this paper describes the creation of mechanisticempirical models for tram tracks (narrow) gauge degradation by adopting the modelling methodology used on the classic railway constructions. Two types of tram tracks are observed: tracks with indirect elastic rail fastening system and stiffer direct elastic rail fastening system. These models represent the first step towards establishing a predictive maintenance system on Zagreb tram tracks.
\end{abstract}

Keywords: tram track; predictive maintenance; monitoring; gauge degradation; exploitation period; mechanistic-empirical model; rail fastening system.

\section{Introduction}

Tram track system management is a complex interdisciplinary process. It involves construction, monitoring and maintenance of track infrastructure and rolling stock, and public transport organization. High costs of track systems implementation result in significant investments in their maintenance. Because of that, the main goal of track system management is to ensure a safe and comfortable ride during long exploitation periods. In the last few decades the number of cities that are (re)introducing the tram system as an effective, adaptable, and ecological public transport system is increasing. Numerous projects for reconstruction of existing, revitalization of historic, and construction of new tram routes prompted the International Association of Public Transport to warn about the following fact (referring to the experiences of the national rail systems managers): only introduction of modern tram track design solutions based on new materials and construction technologies in the long run will not attain the desired effect of establishing a sustainable urban transport system. The development of such sustainable system, geared towards maximisation of service availability and reduction of maintenance costs, requires the simultaneous develop- ment of a modern management system that is based on integration and mutual complementarity of engineering and maintenance activities (UITP 2009). The first step in the optimization of maintenance procedures on tram tracks is increasing the proportion of planned predictive-preventive maintenance at the expense of corrective maintenance (Faiz, Singh 2009; Jovanović et al. 2014). This requires the development of a maintenance-planning model. The basic prerequisite of its establishment is the development of a mathematical model of tram track degradation during exploitation.

Rail track degradation is observed through degradation of individual track components (rails, fastenings, sleepers, ballast) or track geometry parameters (track gauge, cant and cross level, alignment and longitudinal level). Developed degradation models vary from detailed microscopic to macroscopic decision-support systems (Ferreira, Murray 1997) created by probabilistic, mechanistic, and empirical modelling approaches (Andersson 2002). Meanwhile, the knowledge on degradation analysis and modelling of tram tracks has been rudimentary (Ahac 2013; Yousefikia et al. 2014).

In this work the aim was to develop simple model of tram track geometry degradation as the geometry is

Corresponding author: Maja Ahac

E-mail:mahac@grad.hr 
a basic indicator for initiating tram track maintenance procedures. Although its' monitoring and modelling is recognized as a very important part of track management, many tram networks management structures, in an effort to improve their maintenance system, face the following problems:

- The application of the best practice i.e. geometry degradation models developed for classic ballasted rail tracks, would be most desirable. However, the knowledge of track geometry behaviour during exploitation gained in the field of classic rail systems cannot be directly applied to the narrow-gauge tram tracks in urban areas. This is due to the major differences in track design requirements and exploitation conditions, defined as the key geometry degradation influential factors (Ferreira, Murray 1997; Sadeghi, Askarinejad 2007). These differences are observed in the track location, geometry design parameters, construction elements, vehicles, and traffic characteristics (Kopf et al. 2009).

- Many European cities have retained the traditional tram systems that date back to before the First World War. Nowadays, they face the problem of documenting their infrastructure in digital databases, which are the prerequisite for maintenance-planning via degradation models. In addition, the actual knowledge on the tracks condition is limited to a small number of managements' employees, and most of them do not have any tools for collecting, systemizing and integrating data on design, construction, operation and maintenance of the tracks in the historical database on which to conduct the assessment of the maintenance needs (Andersson et al. 2004; Madejski 2005).

Fortunately, cities that have recently upgraded their tram systems into modern networks based on the technologies and practices of urban light rail (Stefanovic 2003) now have a large amount of precise digital documentation necessary for creation of historical databases. One such system is the tram system in the city of $\mathrm{Za}$ greb, with about $80 \mathrm{~km}$ of tram tracks that were built and reconstructed during the last two decades. Today, regular tram traffic in Zagreb is organised in 15 lines which are served daily by 178 tram vehicles operating on $116.3 \mathrm{~km}$ of $1000 \mathrm{~mm}$ gauge tracks. This high capacity tram network presents an optimal testing ground for exploring the possibilities of introducing the predictive maintenance system on narrow-gauge tramway tracks through the development of a track geometry degradation model, based on the principles established on classic rail track structures.

According to regulations (ZET 1997), two track geometry parameters must be monitored on Zagreb tram tracks: track gauge and cant. Track gauge degradation during exploitation is a result of rail wear. In addition to compromising the required driving comfort, gauge degradation causes additional dynamic loads on the tram-track system, and even faster further degrada- tion and higher maintenance costs. It is therefore not surprising that successive inspection and modelling of gauge degradation is the most common form of track geometry condition monitoring within the maintenance procedures (Fortunato et al. 2007; Lyngby 2009). Track cant is a geometry parameter characteristic for the tracks in horizontal curves. Since this research is the first ever attempt of modelling Zagreb tram track geometry behaviour during exploitation, to simplify the process only tangential track segments geometry i.e. track gauge is observed (Fig. 1).

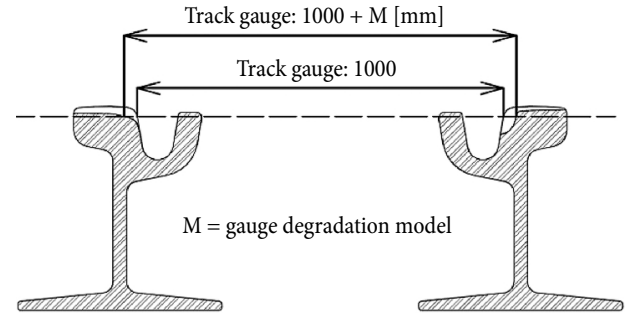

Fig. 1. Tram track gauge degradation modelling

\section{Influential Factors of Tram Track Gauge Degradation}

Track gauge degradation is primarily a result of the dynamic load of the moving vehicle, caused by irregularities on the wheel-rail contact surface and in the track horizontal geometry. The greater the exploitation intensity and rail vehicles speed, the faster is the degradation rate. Elements of horizontal geometry also have a significant effect on track gauge degradation, especially the curvature of track horizontal alignment - track gauge degradation is faster in the horizontal curves than on tangential track segments. Rail wear rate depends on the quality of rail steel, which is defined by its hardness. Installation of higher steel hardness rails slows down the degradation process (Olofsson, Lewis 2006; Sadeghi, Akbari 2006; Faiz, Singh 2009; Sadeghi, Askarinejad 2007; Ferreira, Murray 1997; Marqueteeken et al. 2008; Povilaitienè et al. 2006). Because of that, two types of steel grooved Ri-60 rails are used on Zagreb tram tracks: steel grade R200 rails at tangential and curved tracks with radius $R \geq 200 \mathrm{~m}$ and wear-resistant steel grade R260 rails at curved tracks with radius $R<200 \mathrm{~m}$ (Lakušić, Ahac 2012).

In most cases, tram tracks must be designed in a way that road vehicles could also run on them. This is the main reason why the tram tracks are constructed differently than classic rail tracks. On tram tracks the rails are fixed by fasteners to continuous reinforced concrete foundation slabs, not to individual sleepers laid in the ballast bed as on classic rail tracks. In Zagreb tram system, grooved rails are discreetly laid on the levelling blocks, made out of micro synthetic concrete, which are built on reinforced concrete slab. The distance between levelling blocks is one meter in the tram rolling direction. Rails are fixed to these blocks by different types of fastening systems (Lakušić 2003), commonly by:

- Indirect elastic fastening system, Fig. 2a, with two neoprene rail pads inserted between the rail 
foot and the concrete base. The stiffness of the entire fixing point reaches $40 \mathrm{MN} / \mathrm{m}$. It is used on about $50 \%$ of network.

- Direct elastic fastening system, Fig. 2b, which has only one pad between the rail foot and the concrete base. The stiffness of this fixing point amounts to $140 \mathrm{MN} / \mathrm{m}$. It is used on about $30 \%$ of network.
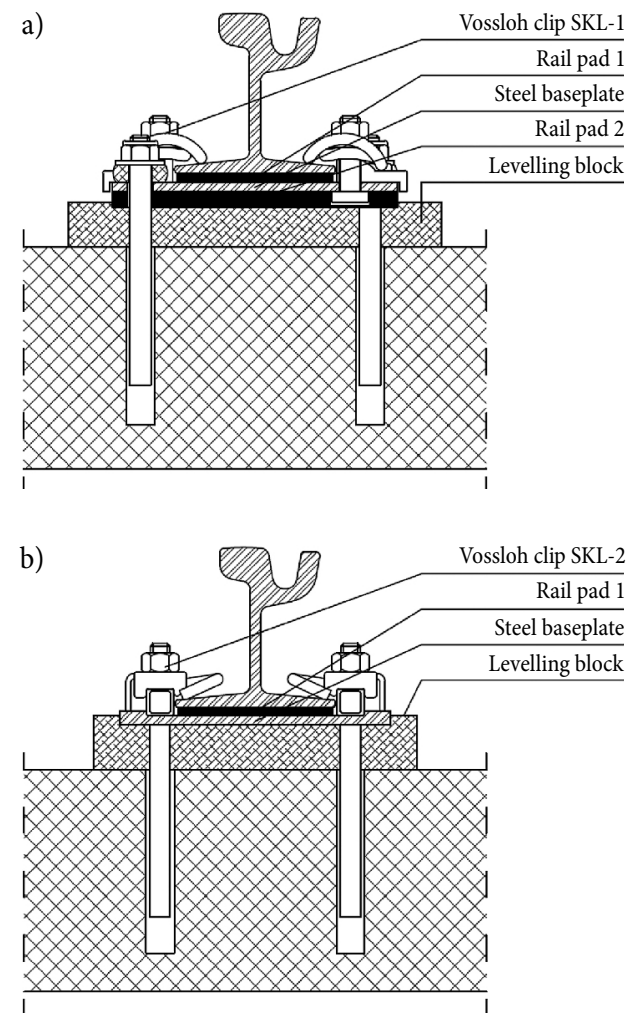

Fig. 2. Commonly used fastening systems on tram tracks in Zagreb (a) indirect elastic fastening system

(b) direct elastic fastening system

It can be argued that increasing the stiffness of the track structure results in an increase of dynamic forces in the track system (Lakušić et al. 2010), and therefore faster track gauge degradation rate during exploitation. This statement must be taken with some caution, since the intensity of the dynamic forces also depends on the rail vehicle load magnitude and frequency. In order to quantify the effect of the fastening systems' stiffness on tram track gauge degradation rate, it was necessary to create a gauge degradation model. This model represents the first step towards establishing a predictive maintenance system on Zagreb tram tracks.

\section{Investigation Approach and Sample}

The analysis of different gauge degradation models development methodologies preformed on classic rail tracks showed that, given the level of detail and manner of collecting and processing the input data required for modelling, development of tram track gauge degradation model should be based on the mechanistic-empirical modelling approach (Sadeghi, Askarinejad 2007). This approach combines engineering and empirical modelling procedures i.e. it uses existing theoretical and empirical (engineering) knowledge about the track gauge degradation influential factors to try to explain empirical (measured) track gauge data (Ahac 2013).

Development of mechanistic-empirical track degradation model is a procedure that requires track segmentation. Track segmentation is a process of dividing linear track infrastructure in segments with homogeneous characteristics of track degradation influential factors and maintenance history (Andersson 2002; Jovanovic 2004; Khouy 2011). For the purpose of this investigation, a review of the available construction and supervision documentation made for the (re)construction of tram tracks in Zagreb in the period 1997-2004 was performed. It resulted in identification of 25 segments along the observed tram tracks, in total length of $4.5 \mathrm{~km}$, suitable for analysis of the effect of applied rail fastening system stiffness on gauge degradation. These segments have homogeneous characteristics of the following gauge degradation influential factors:

- horizontal track alignment curvature (observed track segments are tangential);

- traffic characteristics (segments are in separate tram corridors on which average constant tram speed of $15 \mathrm{~km} / \mathrm{h}$ is achieved, along open track i.e. outside stations and road crossings);

- track superstructure elements (along 18 segments steel grade R200 grooved rails are fixed with indirect elastic fastening system, and along remaining 7 segments with direct elastic fastening system).

\section{Identification of Model Variables}

Mechanistic-empirical model determines the rate of degradation by statistical regression analysis (Jovanovic 2004; Premathilaka et al. 2010). Regression defines the degradation speed of the dependent variable (observed parameter of track quality, e.g. track gauge deviation from prescribed value) as a function of the independent variable (period of tracks exploitation). In this research, the models are based on the results of track gauge monitoring that was performed on different Zagreb tram track segments, constructed with the use of above mentioned various rail fastening systems.

\subsection{Dependent Variable - Measuring of Track Gauge Values}

Analysed construction and supervision documentation made for the purpose and during (re)construction of tram tracks in Zagreb in the period 1997-2004 also contains data about initial track gauge values along observed segments, before tracks exploitation. These values were obtained by continuously measuring the track gauge in the tram vehicles rolling direction, above every discrete rail levelling block i.e. in cross sections located one meter apart from each other. Measurements were preformed after final tightening of the rail fastenings and before paving the track construction. Measured gauge values were denoted with corresponding track station values (geographic locations of gauge measurement 
cross sections along the track) defined in digital georeferenced track design blueprints. Characteristic track gauge measuring cross sections (locations of rail welds, station platforms, and road crossings) were additionally marked. This enabled identification of 25 data sets on the initial track gauge values along the observed segments. Total number of obtained values is 2554 on track segments with indirect elastic fastenings and 1969 on track segments with direct elastic fastenings. In order to determine gauge degradation during track exploitation, continuous gauge measurements in the same track cross sections were repeated on three occasions, during spring months of 2011, 2013 and 2014 (Table 1).

\subsection{Explanatory Variable - Calculation of Track Exploitation Period}

Track exploitation period can be defined either by exploitation time or exploitation intensity (Khouy 2011). Zagreb's tram rolling stock comprises of eight different tram vehicle types (with different capacities and weight). In addition, each tram section is served by a different number of trams per day, in order to accommodate transport demand across the network. Because of that, for the purpose of this research, period of exploitation was defined by the tracks exploitation intensity. Calculation of exploitation intensity was conducted by integrating data from the available Zagreb Municipality Transit System - ZET Ltd. (Zagrebački električni tramvaj - ZET d.o.o.) internal documents. These documents include information about an hourly frequency of vehicles on a single tram line, the daily number of vehicles of a certain type on each tram line, tram lines network maps, and approximations of vehicles capacity utilization.

Cumulative exploitation intensity was defined as the product of a total number of exploitation days and daily gross mass of trams with passengers (in Millions of Gross Tonnes - MGT). Number of exploitation days was defined by track gauge measurements dates on observed track segments (Table 1).

\subsection{Gauge Data Filtration and Compression}

On the basis of the gauge values measured after different exploitation periods, deviation values from the prescribed $1000 \mathrm{~mm}$ track gauge were calculated in each measurement cross section. In order to minimize possible measurement and/or geographical data synchronization errors, two steps of track gauge deviation data filtering were carried out.

In the first step, mean gauge deviation values $\left(\bar{y}_{i}\right)$ and standard deviations $\left(\sigma_{i}\right)$ were calculated for each segment in the corresponding exploitation period $(i=1, \ldots, 53)$. Outliers were identified along each segment as individual gauge deviation values which deviate from the mean of the segment $\bar{y}_{i}$ for more than $3 \sigma_{i}$ (Fig. 3a and Fig. 3b). These outliers were substituted with the first larger or smaller non-outlier gauge deviation value within the same segment.

After the first step of data filtration, gauge deviations differences $\left(y_{d}\right)$ that occurred during the corresponding exploitation period were calculated. The second step of data filtration was performed over these values. This step of the filtration consisted of the same procedure as the first step (Fig. 3c).

During track behaviour modelling by regression analysis, every single-track segment should be treated as a separate 'organism', i.e. it should be allowed to have its own distinct exploitation behaviour characteristics (Jovanovic 2004). In addition, mechanistic-empirical model determines the rate of track degradation by statistical regression analysis over average values of track geometry parameters observed in the track segment (Pedanekar et al. 2003). For these reasons, for each segment exposed to certain exploitation intensity, a compressed mean value of gauge deviation difference $\left(\bar{y}_{d, i}, i=1, \ldots, 53\right)$ was calculated as a representative value for further regression model creation (Fig. 4).

\section{Gauge Data Modelling and Results}

During the gauge data compression process it was observed that the gauge degradation on both analysed types of track structures can be divided into three characteristic phases (Fig. 5). Mild increase in track gauge values in the first phase of the exploitation period is followed by the second, longer-lasting phase of faster gauge degradation. In the third phase, gauge degradation rate is significantly reduced.

Table 1. Calculated exploitation periods for observed track segments

\begin{tabular}{|c|c|c|c|c|c|c|}
\hline \multirow{2}{*}{$\begin{array}{l}\text { Fastening } \\
\text { system }\end{array}$} & \multicolumn{2}{|c|}{ Number of } & \multirow{2}{*}{\multicolumn{2}{|c|}{ Track gauge measurements }} & \multicolumn{2}{|c|}{ Track exploitation period } \\
\hline & Track segments & Measured values & & & Time [days] & Intensity [MGT] \\
\hline \multirow{5}{*}{$\begin{array}{l}\text { Indirect elastic } \\
\text { fastening } \\
\text { system }\end{array}$} & 7 & 1149 & $18 / 04 / 2011$ & $10 / 05 / 2014$ & 1118 & 11.3 \\
\hline & 7 & 714 & $16 / 07 / 2004$ & $17 / 03 / 2013$ & 3167 & 28.9 \\
\hline & 7 & 1149 & $12 / 07 / 1998$ & $18 / 04 / 2011$ & 4664 & 35.1 \\
\hline & 7 & 1149 & $12 / 07 / 1998$ & $10 / 05 / 2014$ & 5782 & 46.4 \\
\hline & 4 & 691 & $25 / 08 / 2004$ & $17 / 03 / 2013$ & 3127 & 80.9 \\
\hline \multirow{3}{*}{$\begin{array}{l}\text { Direct elastic } \\
\text { fastening } \\
\text { system }\end{array}$} & 7 & 1969 & $18 / 04 / 2011$ & $10 / 05 / 2014$ & 1118 & 11.3 \\
\hline & 7 & 1969 & $05 / 06 / 1997$ & $18 / 04 / 2011$ & 5066 & 46.7 \\
\hline & 7 & 1969 & $05 / 06 / 1997$ & $10 / 05 / 2014$ & 6184 & 58.0 \\
\hline Sum & 53 & 10759 & & & & \\
\hline
\end{tabular}


a)

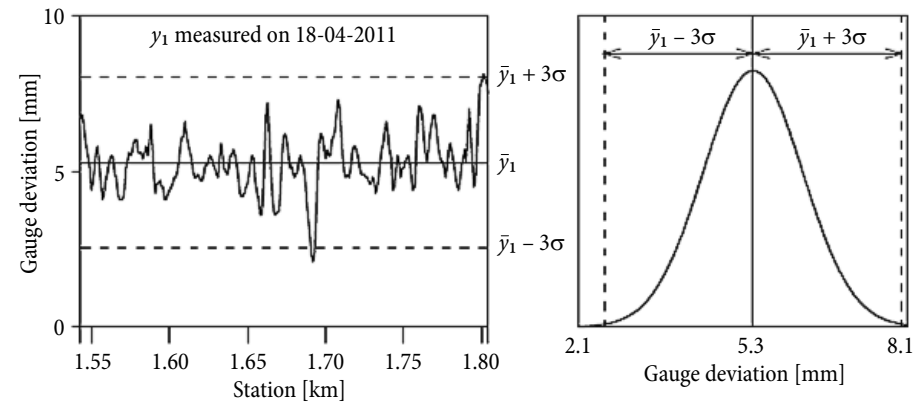

b)

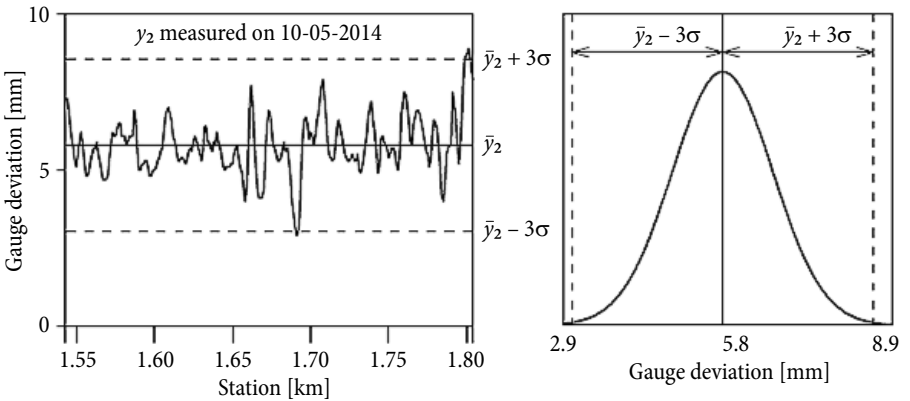

c)

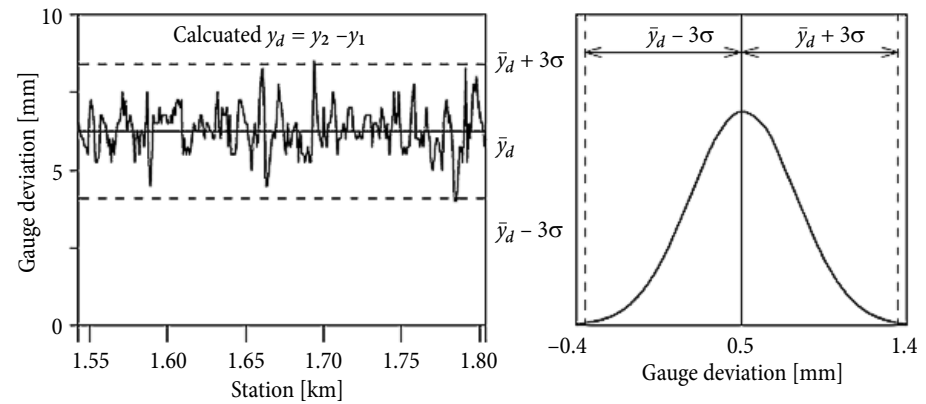

Fig. 3. Example of gauge data filtration on one of the observed track segments

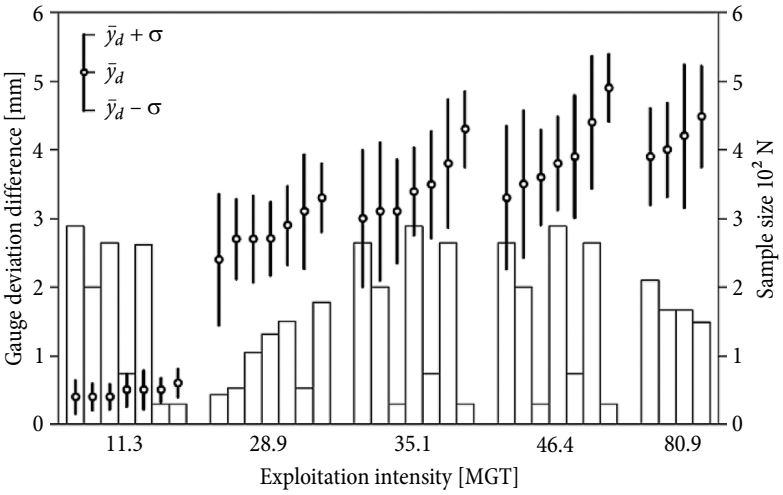

Fig. 4. Results of gauge data compression on different indirect elastic fastening system segments

This corresponds to the results of numerous studies of rail wear phenomena, whose appearance is the main cause of track gauge increase during exploitation. These studies (preformed on classic ballasted tracks) have shown that the process of rail wear is more prominent immediately after the commissioning of the renovated or newly built rail tracks. After a period of considerable rail abrasion, which occurs immediately after their installation or re-profiling, and during which the rail profile adapts to the form of wheel flange, the rail degradation speed is gradually reduced (Esveld 2015).

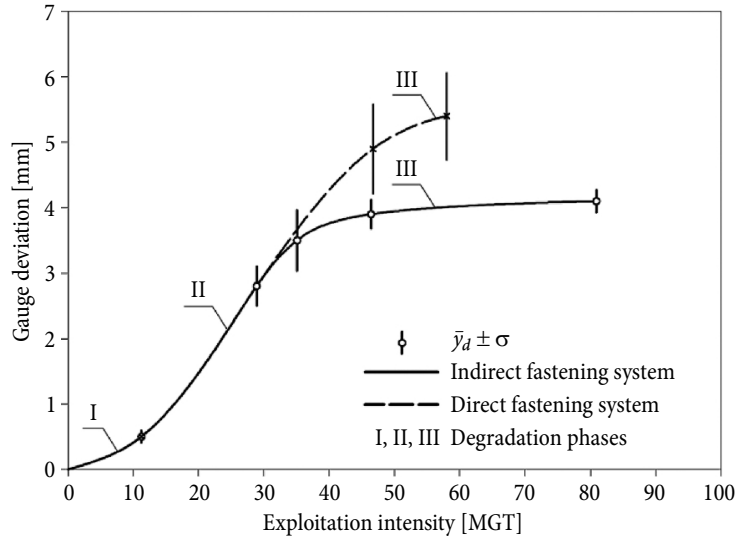

Fig. 5. Observed gauge degradation phases

Because of the observed trend, tram tracks gauge degradation behaviour was modelled separately for each degradation phase and type of track. The same concept of the (linear) degradation for each phase was assumed. Linear degradation models for individual phases of each observed track type were defined using the least squares method (Fig. 6).

Table 2 shows models' results (regression coefficients i.e. regression line slopes) and indicators of their representativeness (determination coefficients, standard errors of the estimates, and regression variability coef- 


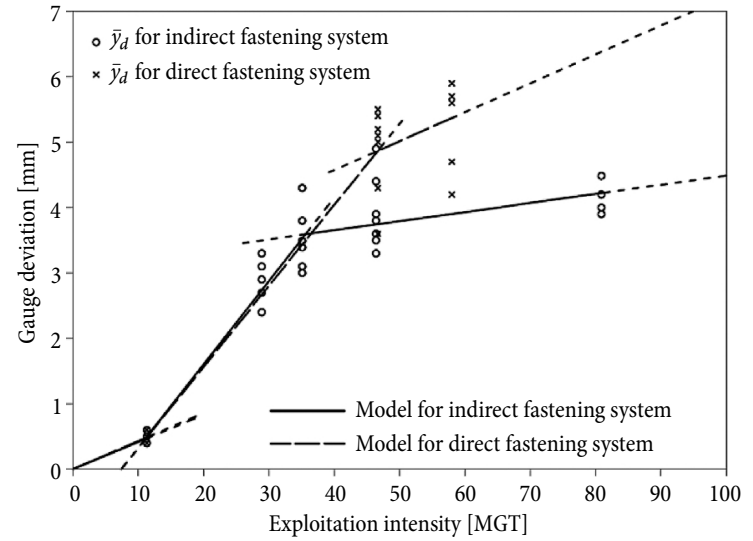

Fig. 6. Linear regression models

ficients). Regression coefficients show an equal rate of gauge degradation in the assumed first and second phases, regardless of the fastening systems stiffness. The difference between the gauge degradation behaviour of different structure types is manifested in a longer second degradation phase of a direct, stiffer fastening system. Considering the indicators of representativeness and the amount of input data, it was concluded that models describe the gauge degradation very well during first and second phases. Improving prediction accuracy in the third degradation phase requires further explorations.

\section{Conclusions}

Results of created models have shown that the correlation between the rate of tram track gauge degradation during exploitation and stiffness of its rail fastening system can be described as follows:

- For values of tram track exploitation intensity to approximately $35 \mathrm{MGT}$, models for both observed systems estimate equal regression coefficients with very high determination coefficients $\left(0.95 \leq R^{2} \leq 0.98\right)$. It can be concluded that in the initial stages of tram track exploitation the effect of fastening system's stiffness on gauge degradation rate is negligible.

- After increase in exploitation intensity above the $35 \mathrm{MGT}$, gauge degradation speed significantly decreases on tracks with indirect elastic fastening systems. On tracks with direct elastic fastening system, reduction in gauge degradation rate oc- curs later, above 45 MGT of exploitation intensity.

- For values of tram track exploitation intensity above 45 MGT, developed models do not provide an accurate prediction of gauge degradation behaviour. Increasing the accuracy of the models requires further tram track gauge monitoring.

In short, modelling results have shown that a period of pronounced gauge degradation during tram track exploitation is shorter in the case of the indirect elastic fastening system with lower stiffness. In this respect, to optimize the track maintenance procedures and extend the life cycle of the tracks, it would be desirable to adjust the track geometry quality control and maintenance cycles according to track stiffness. In addition, when selecting structural elements for new tramway tracks, advantage should be given to indirect elastic rail fastenings.

The overall process of model creation, based on the principles established on the classic rail tracks, pointed out the following challenges. In the first place, the research was limited by the availability and form of the input data about tram tracks required for the creation of database over which the modelling would be carried out. This data was collected and stored over the years by various stakeholders for numerous reasons, other than modelling gauge degradation. Time consuming work on conversion, calculation, analysis, integration, and final synchronization of extensive archive data has resulted in a unique digital georeferenced historical database on the design, construction, and exploitation characteristics of observed tram tracks. It is our recommendation to establish procedures for detailed recording of these characteristics and their integration into a single database prior to any future extensive (re)constructions of tram tracks. Also, keeping track of exploitation parameters of network's individual track sections, compared to the current practice of keeping records of exploitation parameters of tram lines, would significantly accelerate and simplify the process of exploitation intensity calculation. All of this would imply close cooperation between tram network managements design, construction, maintenance, and transport organisation divisions and would result in a gradual increase in portions of network that could serve as a platform for further research and creation of detailed and more precise tram tracks degradation models.

Table 2. Calculated regression coefficients and indicators of model representativeness

\begin{tabular}{|c|c|c|c|c|c|c|}
\hline \multirow{2}{*}{ Phase } & \multirow{2}{*}{ System } & Observations & Regression coefficient & Determination coefficient & Standard error & Variability coefficient \\
\hline & & $\mathrm{N}$ & $\beta$ & $R^{2}$ & $\sigma[\mathrm{mm}]$ & $V[\%]$ \\
\hline \multirow{2}{*}{ I } & Indirect & 8 & 0.04 & 0.98 & 0.1 & 17.0 \\
\hline & Direct & 8 & 0.04 & 0.97 & 0.1 & 19.6 \\
\hline \multirow{2}{*}{ II } & Indirect & 21 & 0.12 & 0.95 & 0.3 & 14.3 \\
\hline & Direct & 14 & 0.12 & 0.96 & 0.5 & 18.2 \\
\hline \multirow{2}{*}{ III } & Indirect & 18 & 0.01 & 0.22 & 0.5 & 12.7 \\
\hline & Direct & 14 & 0.04 & 0.14 & 0.7 & 13.1 \\
\hline
\end{tabular}




\section{Funding}

This work was supported by the Ministry of Science, Education and Sports of the Republic of Croatia within the framework of the Scientific Project 'Noise and Vibrations on Tram and Railway Tracks' (Grant Number 082-0000000-2185).

\section{Disclosure Statement}

Authors declare that they have no competing financial, professional, or personal interests from other parties mentioned in this paper.

\section{References}

Ahac, M. 2013. Mehaničko-empirijski model promjene širine tramvajskog kolosijeka tijekom eksploatacije: Doktorska disertacija. Sveučilište u Zagrebu, Građevinski fakultet, Zagreb. 242 s. (in Croatian).

Andersson, M. 2002. Strategic Planning of Track Maintenance. State of the Art. Report TRITA-INFRA 02-035. KTH Royal Institute of Technology, Sweden. 59 p.

Andersson, M.; Murray, M.; Ferreira, L.; Lake, N. 2004. Collection and use of railway track performance and maintenance data, in New Horizons for Rail: CORE 2004: Conference on Railway Engineering, 20-23 June 2004, Darwin, Australia, 1-9.

Esveld, C. 2015. Modern Railway Track. Digital edition. MRTProductions.

Faiz, R. B.; Singh, S. 2009. Information analysis of rail track for predictive maintenance, WSEAS Transactions on Computers 8(7): 1123-1133.

Ferreira, L.; Murray, M. H. 1997. Modelling rail track deterioration and maintenance: current practices and future needs, Transport Reviews 17(3): 207-221.

http://dx.doi.org/10.1080/01441649708716982

Fortunato, E.; Pinelo, A.; Lobo Costa, J.; Gonçalves, D.; Pratas, A. 2007. Some results of quality indicators of a railway track obtained in its renewal process, in 4th International Società Italiana Infrastrutture Viarie (SIIV), 12-14 Settembre 2007, Palermo, Italia. (CD).

Jovanovic, S. 2004. Railway track quality assessment and related decision making, in 2004 IEEE International Conference on Systems, Man and Cybernetics, 10-13 October 2004, Hague, Netherlands, 6: 5038-5043.

http://dx.doi.org/10.1109/ICSMC.2004.1400992

Jovanović, S.; Božović, D.; Tomičić-Torlaković, M. 2014. Railway infrastructure condition-monitoring and analysis as a basis for maintenance management, Gradevinar 66(4): 347-358. http://dx.doi.org/10.14256/JCE.959.2013

Khouy, I. A. 2011. Optimization of Track Geometry Maintenance: a Study of Track Geometry Degradation to Specify Optimal Inspection Intervals: Licentiate Thesis. Luleå University of Technology, Sweden. 98 p.

Kopf, F.; Maras, I.; Gasser, F.; Norkauer, A.; Ritz, O.; Krüger, F. 2009. Visual Inspection \& Maintenance. Proposal for "European Standard for Track Inspection and Maintenance". Deliverable D2.4. Work Package WP2.2.1. Subproject SP2: Cost Effective Track Maintenance, Renewal \& Refurbishment Methods. Report for Project FP6-31312: Urban Rail Transport (Urban Track).
Lakušić, S. 2003. Dinamički utjecaj vozila na tramvajski kolosijek: Doktorska disertacija. Sveučilište u Zagrebu, Građevinski fakultet, Zagreb. 183 s. (in Croatian).

Lakušić, S.; Ahac, M. 2012. Hardness distribution over crosssection of grooved rails, Gradevinar 64(12): 1009-1018.

Lakušić, S.; Ahac, M.; Haladin, I. 2010. Experimental investigation of railway track with under sleeper pad, in 10. Slovenski kongres o cestah in prometu, 20. - 22. oktobra 2010, Portorož, Slovenia, 386-393.

Lyngby, N. 2009. Railway track degradation: shape and influencing factors, International Journal of Performability Engineering 5(2): 177-186.

Madejski, J. 2005. Light rail, tram track and turnout geometry measurement and diagnostic tools, WIT Transactions on the Built Environment 77: 185-195.

http://dx.doi.org/10.2495/UT050191

Marqueteeken, A.; Van Leuven, A.; Kopf, F. 2008. Preventive Maintenance of Embedded Tram Tracks. Rail Wear in Curves and Special Trackwork for Trams. Deliverable D2.8. Work Package WP2.3. Subproject SP2: Cost Effective Track Maintenance, Renewal \& Refurbishment Methods. Report for Project FP6-31312: Urban Rail Transport (Urban Track).

Olofsson, U.; Lewis, R. 2006. Tribology of the wheel-rail contact, in S. Iwnicki (Ed.). Handbook of Railway Vehicle Dynamics, 121-142.

Pedanekar, N. R.; Venkoba Rao, B.; Kapur, P.; Harbuck, R.; Mischke, M. 2003. Profile-based prediction: an enhanced methodology for prediction of track degradation, in Proceedings of the AREMA 2003: Annual Railroad Conference, 5-8 October 2003, Chicago, IL, US, 302-323.

Povilaitienè, I.; Kamaitis, I. Z.; Podagèlis, I. 2006. Influence of gauge width on rail side wear on track curves, Journal of Civil Engineering and Management 12(3): 255-260.

Premathilaka, A.; Costello, S.; Dunn, R. 2010. Development of a deterministic rail-wear prediction model, Road \& Transport Research: a Journal of Australian and New Zealand Research and Practice 19(1): 40-50.

Sadeghi, J.; Akbari, B. 2006. Field investigation on effects of railway track geometric parameters on rail wear, Journal of Zhejiang University SCIENCE A 7(11): 1846-1855. http://dx.doi.org/10.1631/jzus.2006.A1846

Sadeghi, J.; Askarinejad, H. 2007. Influences of track structure, geometry and traffic parameters on railway deterioration, IJE Transactions B: Applications 20(3): 291-300.

Stefanovic, G. 2003. Review of Light Rail Systems in the World and Analysis of Comparable Cities with Bergen. A Report for City of Bergen. HTM Consultancy. $52 \mathrm{p}$.

UITP. 2009. Life Cycle Cost Optimisation. A UITP (Union Internationale des Transports Publics) Information Sheet. 4 p.

Yousefikia, M.; Moridpour, S.; Setunge, S.; Mazloumi, E. 2014. Modeling degradation of tracks for maintenance planning on a tram line, Journal of Traffic and Logistics Engineering 2(2): 86-91. http://dx.doi.org/10.12720/jtle.2.2.86-91

ZET. 1997. Propisnik o održavanju pruge i pružnih postrojenja. Zagrebački električni tramvaj - ZET d.o.o. (in Croatian). 